University of Nebraska - Lincoln

DigitalCommons@University of Nebraska - Lincoln

2010

\title{
Emotional Intelligence and Transformational and Transactional Leadership: A Meta-Analysis
}

\author{
Peter D. Harms \\ University of Nebraska - Lincoln, pharms@gmail.com \\ Marcus Credé \\ State University of New York at Albany, mcrede@albany.edu
}

Follow this and additional works at: https://digitalcommons.unl.edu/leadershipfacpub

Part of the Management Sciences and Quantitative Methods Commons

Harms, Peter D. and Credé, Marcus, "Emotional Intelligence and Transformational and Transactional Leadership: A Meta-Analysis" (2010). Leadership Institute Faculty Publications. 14.

https://digitalcommons.unl.edu/leadershipfacpub/14

This Article is brought to you for free and open access by the Leadership Institute at DigitalCommons@University of Nebraska - Lincoln. It has been accepted for inclusion in Leadership Institute Faculty Publications by an authorized administrator of DigitalCommons@University of Nebraska - Lincoln. 


\title{
Emotional Intelligence and Transformational and Transactional Leadership:A Meta-Analysis
}

\author{
P. D. Harms \\ University of Nebraska-Lincoln, USA \\ Corresponding author — II4 CBA, I240 R Street, Lincoln, NE 68588; email pharms2@unl.edu
}

\section{Marcus Credé}

State University of New York at Albany, USA

\begin{abstract}
The purpose of this study is to evaluate claims that emotional intelligence is significantly related to transformational and other leadership behaviors. Results (based on 62 independent samples) indicated a validity estimate of .59 when ratings of both emotional intelligence and leadership behaviors were provided by the same source (self, subordinates, peers, or superiors). However, when ratings of the constructs were derived from different sources, the validity estimate was.12. Lower validity estimates were found for transactional and laissez-faire leadership behaviors. Separate analyses were performed for each measure of emotional intelligence. Trait measures of emotional intelligence tended to show higher validities than ability-based measures of emotional intelligence. Agreement across ratings sources for the same construct was low for both transformational leadership (.I4) and emotional intelligence (.16).
\end{abstract}

Keywords transformational, leadership, emotional intelligence

Research into the relationship between emotional intelligence (EI) and transformational leadership is filled with bold claims as to the relationship between these constructs. Noted experts in the field of EI argue that elements of EI such as empathy, self-confidence, and self-awareness are the core underpinnings of visionary or transformational leadership (Goleman, Boyatzis, \& McKee, 2002). An information package distributed by Multi-Health Systems, the leading distributor of EI assessment tools, claims that "emotional intelligence is synonymous with good leadership." Some have claimed that "for those in leadership positions, emotional intelligence skills account for close to 90 percent of what distinguishes outstanding leaders from those judged as average" (Kemper, 1999, p. 16). Others have noted the disappointing results of intelligence and personality models in the prediction of exceptional leadership and have argued that EI may represent an elusive " $X$ " factor for predicting transformational leadership (Brown \& Moshavi, 2005).

Since Goleman (1995) popularized the concept of EI, there has been no shortage of studies investigating the relationship between EI and positive outcomes. Two recent meta-analyses have found positive associations for
EI with school and work performance outcomes (Van Rooy \& Viswesvaran, 2004) as well as mental and physical health (Schutte, Malouff, Thorsteinsson, Bhullar, \& Rooke, 2007). Research into the relationship between EI and leadership outcomes has seen similar, if not more, levels of interest in recent years. The relationship with transformational leadership has received particular attention in these studies, which can be attributed to both its popularity in the leadership literature and specific elements of transformational leadership theory that seem relevant to EI. Yet, there has been widespread skepticism of the link between EI and leadership outcomes (Antonakis, Ashkanasy, \& Dasborough, 2009; Landy, 2005; Locke, 2005) and many studies have failed to find significant relationships between EI and transformational leadership in particular (e.g., Brown, Bryant, \& Reilly, 2006; Moss, Ritossa, \& Ngu, 2006; Sosik \& Megarian, 1999; Weinberger, 2004). A review of the relationship between EI and leadership outcomes described the ongoing debate between the proponents and critics of EI as one that "thrives on hyperbolic claims on one hand, and empirical evidence to the contrary on the other" (Lindebaum, 2009, p. 227). Furthermore, in a recently published debate (An- 
tonakis et al., 2009) between major figures in each camp, Ashkanasy and Dasborough argued that a meta-analysis was needed to establish whether or not the claims of the EI proponents had merit. To address the issues raised in prior research and the current debate, this study will use a meta-analytic approach to establish whether or not EI is related to transformational and transactional leadership behaviors and under what circumstances.

\section{Transformational Leadership}

The concept of transformational leadership, a component of Bass and Avolio's "full range leadership theory" (Antonakis \& House, 2002; Avolio, 1999; Bass, 1998), is one of the most widely researched paradigms in the leadership field and has shown substantial validity for predicting a number of outcomes including leader performance and effectiveness ratings in addition to follower satisfaction and motivation (Judge \& Piccolo, 2004; Sashkin, 2004). Transformational leaders act as mentors to their followers by encouraging learning, achievement, and individual development. They provide meaning, act as role models, provide challenges, evoke emotions, and foster a climate of trust. The five dimensions of transformational leadership are idealized influence (attributed), idealized influence (behavioral), individual consideration, inspirational motivation, and intellectual stimulation (Bass \& Avolio, 1997). Idealized influence (attributed) refers to the socialized charisma of the leader and whether or not he or she is perceived as being confident and committed to high-order ideals. Idealized influence (behavioral) refers to charismatic actions by the leader that are based on values, beliefs, or ideals. Individualized consideration is the extent to which a leader attends to the needs and concerns of his or her followers by providing socio-emotional support. This involves mentoring followers, maintaining frequent contact, encouraging followers to self-actualize, and empowering them. Inspirational motivation is the degree to which leaders inspire and appeal to followers by setting challenging goals and communicating optimism with regard to goal attainment. Intellectual stimulation refers to the extent to which leaders engage in behaviors that cause followers to challenge their assumptions, think creatively, take risks, and participate intellectually.

Beyond the subdimensions of transformational leadership, Bass and Avolio's (1997) full range model of leadership also contains three transactional leadership factors: contingent reward, management-by-exception (active), and management-by-exception (passive). Contingent reward refers to the degree that leaders operate according to economic and emotional exchange principles with followers. The leader sets out clear goals and expectations and rewards followers for working toward them. Managementby-exception (active) is the extent to which a leader actively monitors followers for mistakes and tries to correct them.
Management-by-exception (passive) refers to leaders who wait for mistakes to occur before acting to correct them.

A final style of leadership is laissez-faire leadership, which refers to the absence of leadership. Laissez-faire leaders avoid making decisions or taking positions, hesitate to take action, abdicate their authority, and are typically absent when they are needed. Although conceptually similar to management-by-exception (passive), this form of leadership results in a lack of action even when correction is needed.

It has been noted that leaders can display each of these leadership styles at various times and to various degrees but that effective leaders are described as displaying transformational leadership behaviors and transactional leadership behaviors more frequently than passive and ineffective non-leadership style behaviors (Avolio, 1999).

Although there has been a great deal of research demonstrating the effectiveness of transformational leadership behavior in organizations (Judge \& Piccolo, 2004), there has been a relative lack of research investigating the antecedents of these behaviors (Rubin, Munz, \& Bommer, 2005). Prior research has linked transformational leadership with a number of biographical background factors such as parents taking an active interest in the development of their child, high parental moral standards, and whether or not individuals enjoyed school and their prior work experience (Avolio, 1994). In terms of psychological factors, transformational leadership has been linked with the higher levels of the traits Extraversion, Agreeableness, Emotional Stability, and Openness (Bono \& Judge, 2004) in addition to other individual differences such as Need for Power (Antonakis \& House, 2002; Sashkin, 2004), moral reasoning (Turner, Barling, Epitropaki, Butcher, \& Milner, 2002), and secure attachment style (Popper, Mayseless, \& Castelnovo, 2000). Higher levels of intelligence have also been found to be related to transformational leadership (Atwater \& Yammarino, 1993). However, overall, the capacity of individual differences to predict transformational leadership has been disappointing. A meta-analysis of the relationship between transformational leadership and Big Five traits found that the corrected correlation between these constructs ranged from a low of .09 for Openness to a high of .23 for Extraversion (Bono \& Judge, 2004). As a consequence, it has been suggested that other, unexplored factors such as EI may play a prominent role in predicting transformational leadership behaviors (Bass, 2002; Brown \& Moshavi, 2005; Nye, 2008).

\section{Emotional Intelligence}

Although definitions of EI vary widely, it can be thought of as "the set of abilities (verbal and non-verbal) that enable a person to generate, recognize, express, understand, and evaluate their own and others' emotions in order to guide thinking and action that successfully cope with environmental demands and pressures" (Van Rooy 
\& Viswesvaran, 2004, p. 72). Research has conceived of EI as either a trait (Bar- On, 1997; Goleman, 1995; Petrides \& Furnham, 2000; 2001) or an ability (Salovey \& Mayer, 1990). As a trait, EI is considered to be an innate characteristic that enables and promotes well-being. Trait EI has been described as a constellation of emotional self-perceptions at the lower levels of personality hierarchies (Petrides, Pita, \& Kokkinaki, 2007). As an ability, EI is considered to be important for not only comprehending and regulating emotions, but also understanding and integrating them into cognitions.

Because of differences in definitions, researchers have employed a variety of assessment devices to measure EI. Typically, research into trait EI has used self-report measures such as the Bar-On (1997) Emotional Quotient Inventory or the Swinburne University Emotional Intelligence Test (Palmer \& Stough, 2001). Whereas traitbased measures generally depend on participants self-reporting their levels of EI, ability-based measures such as the Mayer-Salovey- Caruso Emotional Intelligence Test (Mayer, Salovey, \& Caruso, 2002) require participants to engage in tasks that assess EI based on performance. On these measures, participants may be asked to identify the emotions conveyed by pictures, report on how they would manage or change emotions in response to hypothetical scenarios, relate emotions to sensory stimuli, or report on circumstances that would be expected to change emotional states (Mayer, Salovey, \& Caruso, 2004). Responses are then scored according to consensus or expert ratings of the different options.

While there have been considerable efforts made to create psychometrically valid measures of EI, there remains no single universally accepted measure of EI, and a number of criticisms have been made concerning the psychometric properties of the current scales available with regard to their convergent, discriminant, and predictive validity. For instance, Brackett and Mayer (2003) compared a number of different EI inventories and found little convergence across EI measures. Because of this, some researchers have questioned whether or not different measures of EI assess the same construct at all (Matthews, Zeidner, \& Roberts, 2002). Beyond concerns about crossmeasure comparability, Antonakis (2004) has noted that in numerous studies, EI measures fail to add incrementally to the prediction of work outcomes above and beyond established measures of personality and cognitive intelligence. Moreover, concerns have been raised about the susceptibility of trait-based EI measures to faking under high-stakes conditions (Day \& Carroll, 2008).

\section{The Relationship Between Emotional Intelligence and Transformational and Transactional Leadership}

Despite concerns about the various EI measurements themselves, interest in EI remains high, in particular in the leadership domain. A recent meta-analysis has demonstrated that, across criteria, EI has an operational validity of .24 with employment-related criteria (Van Rooy \& Viswesvaran, 2004). Anthropologists have noted that appropriate emotional displays and recognition of the emotional displays of others are essential for successful functioning and leadership in primate societies (Boehm, 1999). Moreover, there are a number of theoretical arguments to be made for the relationship between EI and effective leadership, specifically transformational leadership (Daus \& Ashkanasy, 2005). EI competencies such as self-confidence, self-awareness, transparency, and empathy have been argued to be essential for communicating visionary messages (Goleman et al., 2002). Sosik and Megarian (1999) suggested several aspects of EI that would facilitate transformational leadership. First, empathy may be necessary for transformational leaders who display individual consideration to followers. Second, emotion management may promote positive affect and confidence in followers expressing and generating new ideas. Third, self-aware leaders may possess a greater than average sense of purpose and meaning. Fourth, those skilled at emotional management are also those more likely to put the needs of others ahead of their own personal needs. George (2000) argued that emotional appeals may be used by transformational leaders for inspirational motivation. Others have pointed out that adherence to professional or moral standards of behavior are common aspects of both EI and transformational leadership (Brown et al., 2006).

Hypothesis 1: Emotional intelligence will be positively related to transformational leadership.

While there are less theoretical underpinnings to guide hypotheses concerning the relationship of transactional and laissez-faire styles of leadership with EI, it has been suggested that to provide the effective and equitable exchanges characteristic of contingent reward behaviors, leaders should have abilities and traits associated with elevated EI (Barling, Slater, \& Kelloway, 2000). Because active management-by-exception behaviors reflect reactive and routine leadership behaviors that require no insight or empathy, it is not expected that there would be any relationship with EI (Barling et al., 2000). However, it is expected that EI would show negative relationships with passive management-by-exception and laissez-faire leadership behaviors, because individuals with elevated EI are thought to be higher on initiative and self-efficacy (Goleman et al., 2002).

Hypothesis 2: Emotional intelligence will be positively related to contingent reward behaviors.

Hypothesis 3: Emotional intelligence will be negatively related to management-by-exception (passive) and laissez-faire leadership behaviors. 


\section{Method}

\section{Literature Search}

Possible sources of data for this study were identified via searches of the PsychINFO (1872-2009), Dissertation Abstracts (1980-2009), Business Sources Premier, and ERIC databases as well as Internet searches for additional unpublished data sources. Keywords used for these searches included emotional intelligence, transformational leadership, multifactor leadership questionnaire, and charismatic leadership. The citation lists of all examined journal articles, technical reports, and dissertations were also examined for additional promising sources. This initial search yielded a total of 106 articles, dissertations, and technical reports.

Studies were only included if they reported zero-order correlations or data from which unbiased estimates of zero-order correlations could be computed. Studies that reported statistically significant correlations, but not nonsignificant correlations, were not included in our analysis; the inclusion of such studies would result in upwardly biased meta-analytic estimates of the strength of relationships. We attempted to contact the authors of all studies that did not present data in a manner that allowed inclusion in our analysis and requested full zero-order correlations for all relevant variables such that their data could be included.

We also decided to include only studies that reported data from explicit measures of EI. Some authors (e.g., Hoffman \& Frost, 2006) have used measures of personality as proxies for measures of EI, but such studies were not included in our analysis.

\section{Coding Procedures}

All studies were coded by the two authors using strict coding procedures and coding sheets to ensure a high level of accuracy and rating agreement. Accuracy checks revealed near unanimous agreement in the coding of all relevant variables. Coded information included correlations, reliability estimates, sample size, the source of both EI and leadership ratings, and the inventories used to assess EI and leadership. Where relevant, we also coded intercorrelations among facet scores of EI and leadership inventories to allow us to calculate unit-weighted composites for those studies that only reported correlations at the facet level.

Our final database was comprised of correlations derived from 62 independent samples, representing data from 7,145 leaders. The Multifactor Leadership Questionnaire (MLQ, Bass \& Avolio, 1995) was the most frequently used measure of transformational leadership $(k=39)$ with only one other inventory, the Leadership Practices Inventory (LPI, Kouzes \& Posner, 2003), being used in more than one study $(k=7)$. A large variety of inventories were used to assess EI with the most frequently used being the
Mayer-Salovey-Caruso Emotional Intelligence Test (MSCEIT, Mayer et al., 2002) ( $\mathrm{k}=12)$, Wong and Law's (2002) Emotional Intelligence Scale (WLEIS, $\mathrm{k}=7$ ), the Bar-On (1997) Emotional Quotient Inventory (BOEQI, $\mathrm{k}=8$ ), the Emotional Intelligence Appraisal $(\mathrm{k}=3)$, and the Swinburne University Emotional Intelligence Test (SUEIT, Palmer \& Stough, 2001) $(\mathrm{k}=4)$.

\section{Analytic Procedure}

The Hunter and Schmidt (1990, 2004) psychometric meta-analytic method was used in this study. This method allows estimation of the amount of variance attributable to sampling error and artifacts such as unreliability in both the predictor (EI) and criterion (leadership) variables, while also providing the best estimates of the population correlations in the absence of measurement error (i.e., $\rho$ ). Because not all studies reported reliability data, we used reliability estimates from those studies that did report internal consistency estimates to create artifact distributions for both the predictor and criterion variables. That is, rather than correct individual correlations using the relevant sample reliability estimates, we corrected the distribution of correlations using the distributions of reliability estimates for the criterion and predictor variables (i.e., the interactive meta-analytic procedure; Hunter \& Schmidt, 1990) to improve the accuracy of the results. For cases in which subscale composites were formed, we calculated Mosier (1943) reliability estimates when subscale intercorrelations were available and used the mean of the subscale reliabilities if the intercorrelations were not available.

By correcting robs and SDobs for measurement error and measurement error variability, we were able to examine whether the variability in observed correlations is due to systematic artifactual biases or reflects the existence of substantive moderators. Moreover, correcting SDobs for the occasionally substantial differences in sample sizes across studies yields a more accurate estimate of whether or not the differences observed in the literature are merely the result of sampling error. At the same time, we note that readers should be cautious when interpreting $S D \rho$ estimates as indicators of moderator effects, especially for meta-analyses with a small number of studies, as is the case for some of our analyses (Oswald \& Johnson, 1998).

\section{Results}

\section{Emotional Intelligence and Transformational Leadership}

Meta-analytic results for the relationship between EI and transformational leadership are shown in Table 1. A visual inspection of the data showed a clear difference in the size of correlations between those studies that relied on same-source ratings for both EI and transformational 
Table I. Relationships Between Overall Emotional Intelligence and Transformational Leadership

\begin{tabular}{|c|c|c|c|c|c|c|c|c|}
\hline & $\begin{array}{l}\text { Source of El } \\
\text { and TL Ratings }\end{array}$ & $k$ & $N$ & $\bar{r}$ & $\rho$ & $S D \rho$ & $10 \% \mathrm{CV}$ & $90 \% \mathrm{CV}$ \\
\hline All samples & & 62 & 7,145 & 0.36 & 0.41 & 0.26 & 0.08 & 0.74 \\
\hline All samples & different & 22 & 2,661 & 0.11 & 0.12 & 0.04 & 0.07 & 0.17 \\
\hline MLQ only & same & 33 & 3,999 & 0.47 & 0.54 & 0.21 & 0.27 & 0.81 \\
\hline Managers and higher only & different & 14 & 2,013 & 0.08 & 0.09 & 0.01 & 0.08 & 0.10 \\
\hline Ability-based El Measure & same & 10 & 1,066 & 0.20 & 0.24 & 0.00 & 0.24 & 0.24 \\
\hline Ability-based El Measure & different & 4 & 441 & 0.04 & 0.05 & 0.00 & 0.05 & 0.05 \\
\hline Trait-based El Measure & same & 38 & 4,424 & 0.58 & 0.66 & 0.19 & 0.42 & 0.91 \\
\hline Published only & different & 12 & $\mathrm{I}, 182$ & 0.14 & 0.16 & 0.08 & 0.06 & 0.26 \\
\hline
\end{tabular}

EI = overall emotional intelligence; $T L=$ overall transformational leadership; $k=$ number of correlations; $N=$ combined sample size; Mean $\bar{r}$ = mean uncorrected correlation; $\rho=$ estimated true score correlation; $S D \rho=$ standard deviation of estimated true score correlation; $C V=$ credibility interval; MLQ = Multifactor Leadership Questionnaire.

leadership and those that used multi-source ratings (i.e., EI ratings and transformational leadership ratings came from different sources). The most typical of these studies were designs that relied on self-ratings for both EI and transformational leadership (same-source) and designs that relied on self-ratings of EI and subordinate- or peerratings of transformational leadership (multi-source). We therefore conducted separate meta-analyses for samesource and multi-source data.

The relationship between EI and transformational leadership was moderately strong for correlation; $\mathrm{CV}=$ credibility interval; MLQ= Multifactor Leadership Questionnaire. The relatively large $S D \rho$ value for same-source ratings suggested the possible presence of substantive moderator effects, and we therefore also conducted separate meta-analyses to compare the effects of different measures on the estimated relationship.

\section{Effect of Leader Rank}

A number of studies in our analysis used coaches, principles, ministers, nurses, supervisors, and student leaders for their samples. To test whether or not the relationship between EI and transformational leadership was moderated by type of leader, we ran separate analyses for those samples that specifically used managers and higher-ranking positions in the business sector and those that used other types of leaders. The results of these meta-analyses are presented in Table 1. For leaders with management positions or higher, there was a strong relationship when same source ratings were used $(k=33, N=3,626, \rho=.52)$, but a weak relationship when multi-source ratings were used ( $k=14, N=2,013, \rho=.08$ ). These results were only slightly smaller than those of the full sample.

\section{Effect of Type of Emotional Intelligence Assessed}

To evaluate the potential moderating effect of different types of EI, we conducted separate analyses of the relationship between leadership style for trait-based and ability-based measures of EI. The results of these meta-analyses are presented in Table 1. Both types of EI measures showed markedly lower validity estimates when multisource ratings were used. For trait-based measures of EI, effects for same source ratings showed a strong relationship ( $k=38, N=4,424, \rho=.66$ ) between EI and transformational leadership, but a weak relationship for multisource ratings $(k=20, N=2,491, \rho=.11)$. Ability-based measures of EI showed lower validity estimates than trait-based measures when same-source ratings were used ( $k=10, N=1,066, \rho=.24$ ) and had no relationship with transformational leadership when multi-source ratings were used $(k=4, N=441, \rho=.05)$.

\section{Effect of Publication Type}

It is often assumed that meta-analyses overestimate validity relationships because they tend to be derived from published sources with significant effects. Similar studies that failed to find those effects tend to remain un- 
Table 2. Relationships Between Transformational Leadership and Emotional Intelligence Moderated by Rating Source and Emotional Intelligence Measure

\begin{tabular}{llrrrrrrr}
\hline Measure & Rating Source & $k$ & $N$ & $\bar{r}$ & $\rho$ & SD $\rho$ & I0\% CV & $90 \%$ CV \\
\hline MSCEIT & Same & 10 & 1,066 & 0.20 & 0.24 & 0.00 & 0.24 & 0.24 \\
MSCEIT & Different & 4 & $44 I$ & 0.04 & 0.05 & 0.00 & 0.05 & 0.05 \\
WLEIS & Same & 6 & 564 & 0.49 & 0.54 & 0.13 & 0.37 & 0.70 \\
WLEIS & Different & 5 & 1,099 & 0.08 & 0.09 & 0.00 & 0.11 & 0.11 \\
BOEQI & Same & 6 & 640 & 0.56 & 0.67 & 0.08 & 0.58 & 0.77 \\
BOEQI & Different & 4 & 267 & 0.18 & 0.20 & 0.12 & 0.05 & 0.35 \\
SUEIT & Same & 4 & 512 & 0.50 & 0.50 & 0.10 & 0.37 & 0.64 \\
EIA & Same & 3 & 135 & 0.45 & 0.47 & 0.28 & 0.11 & 0.83
\end{tabular}

No reliability information available from included studies for this analysis. $k=$ number of correlations; $N=$ combined sample size; $\bar{r}=$ mean uncorrected correlation; $\rho=$ estimated true score correlation; $S D \rho=$ standard deviation of estimated true score correlation; $C V=$ credibility interval; MSCEIT = Mayer-Salovey-Caruso Emotional Intelligence Test; WLEIS = Wong and Law Emotional Intelligence Scale; BOEQI = Bar-On Emotional Quotient Inventory; SUEIT = Swinburne University Emotional Intelligence Test; EIA = Emotional Intelligence Appraisal.

published and, therefore, meta-analyses "oversample" larger effects. This is known as the "file drawer" problem. In this study, the majority of studies used in the overall meta-analysis were from unpublished sources such as dissertations. As a consequence, it is unlikely that these results represent an overestimate of the true relationship between EI and transformational and transactional leadership. Nevertheless, we tested the effect of publication source to establish whether there was any bias in the effect sizes reported in published studies. The results of this analysis can be found in Table 1 . When comparing studies that used same-source ratings, the results were strikingly similar for publication types. Both unpublished $(k=35, N$ $=4,115, \rho=.59)$ and published studies $(k=11, N=1,220$, $\rho=.55)$ showed high effect sizes. However, when multisource ratings were used, both unpublished $(k=10, N=$ $1,476, \rho=.09)$ and published studies $(k=12, N=1,182, \rho$ $=.16$ ) showed substantially lower validity estimates with transformational leadership.

\section{Effect of Emotional Intelligence Inventory}

To assess the potential moderating effect of specific inventories of EI on the relationship between EI and leadership style, we conducted separate analyses of the relationship for each of the most frequently used inventories of EI. The results of these meta-analyses are presented in Table 2. The number of studies and total sample sizes for each of these analyses were relatively small and results should be interpreted with some caution; nevertheless, it appears that the EI-transformational leadership relationship was significantly weaker for the MSCEIT than for other inventories. It should be noted that although $S D \rho$ estimates are zero for some relationships in Table 2, these should not be interpreted to necessarily mean the complete absence of variability across situations. Rather, they are an artifact of the Hunter and Schmidt (1990) meta-analytic method for analyses involving a small number of studies.

\section{Effect of the Multifactor Leadership Questionnaire}

Given the preponderance of the MLQ as the measure of transformational leadership in this area we also conducted meta-analyses of the studies that assessed the relationship between EI and the MLQ. Results for these metaanalyses are also presented in Table 1 with the size of relationships being largely unchanged. For same-source ratings the relationship was of moderate strength $(k=$ $33, N=3,999, \rho=.54)$, while it remained weak for multisource ratings $(k=14, N=1,549, \rho=.09)$.

In addition to this, we also conducted meta-analyses of the subscales of transformational leadership and the other components of the full range model of leadership assessed by the MLQ. The results for these meta-analyses are presented in Table 3.

For the facets of transformational leadership, the pattern of results was largely the same as for overall transformational leadership. That is, for same-source data, the observed relationships were of moderate strength while being of low strength for multi-source data. EI exhibited weak relationships with both management-by-exception (passive) and management-by-exception (active), although the negative relationship with management-byexception (passive) was so strong that the $90 \%$ credibility intervals for both same-source and multi-source data did not contain zero. EI exhibited a moderately strong negative relationship with Laissez-Faire leadership for same-source ratings $(k=14, N=1,304, \rho=-.36)$ and a weak relationship for multi-source ratings $(k=8, N=$ $617, \rho=-.17)$.

\section{Interrater Agreement}

Given the substantial and consistent differences in the strength of observed relationships for same-source and multi-source ratings, we decided to examine the level of agreement between self-ratings and other-ratings in more 
Table 3. Relationships Between Multifactor Leadership Questionnaire (MLQ) Components and Overall Emotional Intelligence Moderated by Rating Source

\begin{tabular}{|c|c|c|c|c|c|c|c|c|}
\hline MLQ Subscale & Rating Source & $k$ & $N$ & $\bar{r}$ & $\rho$ & $S D \rho$ & $10 \% \mathrm{CV}$ & $90 \% \mathrm{CV}$ \\
\hline Idealized influence (attributed) & different & 2 & 284 & -.00 & -.00 & .00 & -.00 & -.00 \\
\hline Idealized influence (behavioral) & different & 2 & 284 & .00 & .00 & .00 & .00 & .00 \\
\hline Idealized influence (overall) & same & 17 & 1815 & .33 & .42 & .15 & .22 & .61 \\
\hline Idealized influence (overall) & different & 7 & 730 & .08 & .10 & .00 & .10 & .10 \\
\hline Individual consideration & different & 7 & 730 & .08 & .10 & .10 & -.02 & .22 \\
\hline Inspirational motivation & same & 17 & 1814 & .36 & .43 & .16 & .23 & .63 \\
\hline Inspirational motivation & different & 7 & 730 & .12 & .14 & .15 & -.05 & .33 \\
\hline Intellectual stimulation & same & 17 & 1815 & .32 & .40 & .15 & .21 & .59 \\
\hline Intellectual stimulation & different & 7 & 730 & .08 & .10 & .00 & .10 & .10 \\
\hline Management by exception (passive) & same & 10 & 871 & -.17 & -.22 & .06 & -.30 & -.14 \\
\hline Management by exception (passive) & different & 3 & 333 & -.09 & -.12 & .00 & -.12 & -.12 \\
\hline Laissez faire & same & 13 & 1204 & -.30 & -.37 & .18 & -.60 & -.14 \\
\hline Laissez faire & different & 8 & 617 & -.12 & -.17 & .00 & -.17 & -.17 \\
\hline Extra effort & same & 8 & 869 & .31 & .36 & .20 & .11 & .61 \\
\hline Extra effort & different & 3 & 304 & .14 & .18 & .15 & -.01 & .37 \\
\hline Effectiveness & same & 8 & 869 & .32 & .37 & .17 & .15 & .60 \\
\hline Effectiveness & different & 3 & 304 & .10 & .14 & .06 & .06 & .21 \\
\hline Satisfaction & same & 8 & 869 & .31 & .35 & .20 & .09 & .61 \\
\hline Satisfaction & different & 3 & 304 & .09 & .12 & .10 & -.01 & .25 \\
\hline
\end{tabular}

$k=$ number of correlations; $N=$ combined sample size; $; \bar{r}=$ mean uncorrected correlation; $\rho=$ estimated true score correlation; $S D \rho=$ standard deviation of estimated true score correlation; $\mathrm{CV}=$ credibility interval.

Table 4. Relationships Between Self and Other Ratings for Emotional Intelligence and Transformational Leadership

\begin{tabular}{llllllll}
\hline Rating Construct & $k$ & $N$ & $\bar{r}$ & $\rho$ & $S D \rho$ & $10 \%$ CV & $90 \%$ CV \\
\hline Emotional intelligence & 3 & 175 & .15 & .16 & .00 & .16 & .16 \\
Transformational leadership & 4 & 202 & .12 & .14 & .05 & .07 & .21 \\
\hline$k$
\end{tabular}

$k=$ number of correlations; $N=$ combined sample size; $\bar{r}=$ mean uncorrected correlation; $\rho=$ estimated true score correlation; $S D \rho=$ standard deviation of estimated true score correlation; $\mathrm{CV}=$ credibility interval.

detail for both EI and transformational leadership. Eight data sources provided relevant data: Barbuto and Burbach (2006); Buford (2001); Burbach (2004); Danehy (2005); Elbers (2007); Fox, Staebler Tardino, and Maloney (2008); Sosik and Megarian (1999); and Wu, Liu, Song, and Liu (2006).

For these data, we calculated meta-analytic estimates of interrater agreement self-ratings and other-ratings of both EI and transformational leadership. The results for this analysis (see Table 4 ) show very low levels of agreement between self- and other-ratings of both EI $(\rho=.16)$ and transformational leadership $(\rho=.14)$.

\section{Discussion}

Given the widespread interest surrounding EI as a predictor of organizational outcomes, and leadership in particular (Spector, 2005), we examined the relationship between EI and transformational leadership, along with other components of the full range model of leadership (Bass \& Avolio, 1997). Recently, it was argued that "leadership theory and research have not adequately considered how leaders' moods and emotions influence their effectiveness as leaders" (George, 2000, p. 1028). The resulting studies conducted using EI measures to address 
this deficit have produced somewhat mixed results. Some have taken the positive findings as proof that EI was significantly related to transformational leadership (Daus \& Ashkanasy, 2005), whereas others remain entirely skeptical of the validity of the construct of EI itself, much less its role in leadership outcomes (Locke, 2005). In such a situation, where the results of empirical research are not entirely clear, meta-analyses can offer insight into the possible reasons for such confusion in addition to providing a more precise estimate of the relationships in question.

Overall, our results linking EI with transformational leadership variables were not as strong or as compelling as advocates of EI testing predicted. Although we found a moderate relationship between EI and transformational leadership behaviors, this was only present for studies where results may have been inflated by the methodological confounds of common method bias and socially desirable responding. In studies where the raters of EI and transformational leadership were not the same, the relationship was small but significant, with effect sizes comparable to those found between personality traits and transformational leadership (Bono \& Judge, 2004).

Across the various facets of transformational leadership, the results were broadly the same with studies using same-source raters showing moderate effects and studies using multiple raters showing small or nonsignificant effects. For other components of the full range model of leadership (Bass \& Avolio, 1997), the results of our meta-analysis broadly supported our hypotheses. Contingent reward had a positive relationship with EI at comparable levels to that of transformational leadership. Management-by-exception (active) showed no significant relationship with EI, and the passive forms of leadership, management-by-exception, and laissez-faire leadership were negatively related to EI.

Where data were available, we tested to see whether the type of EI being assessed or the use of a particular EI measure had an effect on the validity estimates. Overall, trait measures of EI were more strongly related to transformational leadership for both same-source and multisource ratings than were ability-based measures of EI. The Bar-On (1997) Emotional Quotient Inventory had the highest validity estimate for both methods. Both trait- and ability-based measures showed similar reductions in validity when multiple sources for raters were used.

We also tested whether or not organizational rank of the leader being assessed affected the validity of EI ratings. Results showed that there was little difference in validity estimates when only those who were ranked manager or above were considered. One other potential moderator, source of publication, also failed to show any significant effects on the results.

It was noted that the self-other agreement for both EI and transformational leadership was quite low. This was not entirely unexpected as prior studies of self-other agreement on transformational leadership have found similar or even lower levels of consensus (Atwater \& Yammarino, 1992). In a similar way, prior research has demonstrated that observable traits, such as extraversion, show higher levels of consensus across raters than do less observable traits such as emotional stability (Funder, 1995; John \& Robins, 1993). Moreover, Watson and colleagues (Watson, Hubbard, \& Wiese, 2000) have shown that self-other agreement for positive and negative emotions is typically lower than that of Big Five traits. Low agreement across sources is not indicative of lack of validity. Sources can differ in their estimates or attributions of behavior and still show validity if they are using different cues (Funder, 1995). It has been argued that one of the reasons that there is seldom much agreement on ratings of leadership effectiveness is that different kinds of raters use different criteria (Hogan, Curphy, \& Hogan, 1994). For instance, subordinates tend to base their assessments of leader effectiveness on the character and trustworthiness of the leader, whereas their upper level supervisors base their ratings of effectiveness on technical competence and productivity. Nonetheless, the lack of consensus across raters of each of the constructs of interest could partially explain the lower validity estimates seen in studies where multiple raters were used.

Although these results fail to support some of the more extreme claims of EI proponents concerning the potential role of EI in effective leadership, they did not rule out the possibly that EI may play an important role. Although there have been a number of studies conducted assessing the role of EI in transformational leadership, very few have actually been conducted using each of the different measures of EI. Moreover, for each measure of EI, almost no studies have been conducted using a multimethod framework, so comparisons of effect size estimates across methods are not entirely reliable. As newer EI assessment tools are developed and older tests are refined with criteria prediction in mind, it could be expected that validities will improve. Indeed, it has been pointed out that it is unfair to judge the current state of research in EI using results from early measures (Ashkanasy \& Daus, 2005). Nevertheless, these results do reflect the current state of research aimed at linking EI to both transformational and transactional leadership.

It must also be noted that this meta-analysis has limitations that may have affected the results. One potential problem is that, to date, there exists no well-designed study that validates the proposed EI-leadership relationship (Antonakis et al., 2009). For example, the majority of the studies that were used in this meta-analysis relied on self-reports as both predictors and criteria. As shown in the results of this study, this has resulted in greatly inflated validity estimates of the EI-leadership relationship compared with studies that used a more rigorous multimethod approach and the passive forms of leadership, management- 
by-exception (passive) and laissez-faire leadership were negatively related to EI. In addition to this, the majority of studies used in this investigation were from unpublished sources such as dissertations and may have lacked the methodological rigor seen in peer-reviewed publications. Although this is a potential concern, we did not find substantially different validity estimates across the two types of sources. A related concern is that there may be a number of unpublished studies that we were unable to include in this study and that these studies may have shown divergent effects from those reported here. Although this is also a concern, we note again that the majority of studies in this meta-analysis were from unpublished sources and that no substantial difference was found between published and unpublished sources.

Despite these generally weak results, this study does suggest a number of theoretical implications for further research on the topic of the potential effect of EI on transformational leadership or any number of other leadership outcomes. First, it is essential that researchers select their criteria appropriately (Landy, 2005) and assess phenomena using the most relevant source (Roberts, Harms, Smith, Wood, \& Webb, 2006). EI, which occurs mostly within the individual, should be assessed using self-reports or performance data. Transformational leadership measures, on the other hand, are behavioral in nature and best studied from the point of view of those who are meant to be affected by them. As a consequence, further research needs to focus more on using multiple ratings sources to establish an accurate picture of the nature of this relationship. Second, only in rare cases was EI tested for incremental validity above and beyond measures of intelligence and personality. Given that previous research has demonstrated that measures of EI often fail to add validity beyond such measures (Antonakis, 2004; Antonakis et al., 2009), further research aiming to test the relationship between EI and leadership would benefit from such controls. Third, only a few of the studies included in this meta-analysis were conducted outside the United States and almost none outside the English-speaking world. Further research needs to make efforts to test the validity of EI and related constructs in different cultural contexts to establish the universality and possible cultural moderators of the phenomena under investigation (Sadri, Weber, \& Gentry, 2008). Finally, further research should look for possible moderators of the relationship between EI and transformational leadership such as the intensity of emotional displays or the role of gender and age of leaders and followers.

In terms of practical implications, this study suggests that the claims made by EI proponents are largely overstated, in particular those who market EI assessment tools as management screening or training devices. It has even been suggested that "given the sparse empirical evidence, it is unethical and unconscionable to use these measures in applied settings" (Antonakis et al., 2009, p. 248). In fact, even noted proponents of EI have stated that "management practitioners need to take care that they do not overemphasize the predictive value of emotional intelligence in workplace settings" (Jordan, Ashton-James, \& Ashkanasy, 2006, p. 205). Given these concerns and the limited evidence of the effectiveness of EI instruments as predictors of effective leadership styles, we would suggest that EI assessment devices be limited to usage for encouraging self-awareness and self-reflection in managers until better EI measures can be developed and validated.

In summary, the results of this study provide the first meta-analytic estimate of the relationship between EI and transformational and transactional leadership behaviors. Results indicate generally moderate validities when common method variance is present and low validities when common method variance is absent. EI was positively related to the various dimensions of transformational leadership and contingent reward behaviors but was either unrelated or negatively related to management-by-exception or laissez-faire leadership behaviors. Furthermore, we found that trait-based assessments of EI demonstrated higher levels of validity than did ability-based measures and that there was little agreement across raters for ratings of either EI or transformational leadership. Given the preponderance of evidence, it is evident that claims of EI being the core of transformational leadership were overstated, but this study does demonstrate that EI may contribute to successful leadership at some level.

\section{References}

References with an asterisk [*] indicate studies included in the meta-analyses.

Antonakis, J. (2004). On why "emotional intelligence" will not predict leadership effectiveness beyond IQ or the "Big Five": An extension and rejoinder. Organizational Analysis, 12, 171-182.

* Antonakis, J. (2009). Which traits matter for the full-range leadership model? Paper presented at the European Congress of Work and Organizational Psychology, Santiago.

Antonakis, J., Ashkanasy, N., \& Dasborough, M. (2009). Does leadership need emotional intelligence? The Leadership Quarterly, 20, 247-261.

Antonakis, J., \& House, R. (2002). The full-range leadership theory: The way forward. Transformational and Charismatic Leadership, 2, 3-33.

Ashkanasy, N., \& Daus, C. (2005). Rumors of the death of emotional intelligence in organizational behavior are greatly exaggerated. Journal of Organizational Behavior, 26, 441-452.

Atwater, L., \& Yammarino, F. (1992). Does self-other agreement on leadership perceptions moderate the validity of leadership and performance predictions? Personnel Psychology, 45, 141-164. 
Atwater, L., \& Yammarino, F. (1993). Personal attributes as predictors of superiors' and subordinates' perceptions of military academy leadership. Human Relations, 46, 645-668.

Avolio, B. (1994). The "natural": Some antecedents to transformational leadership. International Journal of Public Administration, 17, 1559-1581.

Avolio, B. (1999). Full leadership development: Building the vital forces in organizations. Thousand Oaks, CA: Sage.

* Bailie, K., \& Ekermans, G. (2006). An exploration of the utility of a self-report emotional intelligence measure. E-Journal of Applied Psychology: Emotional Intelligence, 2, 3-11.

Bar-On, R. (1997). The Bar-On Emotional Quotient Inventory (EQi): A Test of Emotional Intelligence. Toronto, Canada: MultiHealth Systems.

* Barbuto, J. E., \& Burbach, M. E. (2006). The emotional intelligence of transformational leaders: A field study of elected officials. The Journal of Social Psychology, 146, 51-64.

* Barfoot, D. S. (2007). Antecedents of leader-follower trust in a Christian church organization. Unpublished dissertation, Regent University, Virginia Beach, VA.

* Barling, J., Slater, F., \& Kelloway, E. K. (2000). Transformational leadership and emotional intelligence: An exploratory study. Leadership and Organization Development Journal, 21, 157-161.

Bass, B. (1998). Two decades of research and development in transformational leadership. European Journal of Work and Organizational Psychology, 8, 9-32.

Bass, B. (2002). Cognitive, social and emotional intelligence of transformational leaders. In R. E. Riggio, S. E. Murphy, \& F. J. Pirozzolo (Eds.), Multiple intelligences and leadership (pp. 105-118). Mahwah, NJ: Lawrence Erlbaum.

Bass, B., \& Avolio, B. (1997). Full range leadership development: Manual for the Multifactor Leadership Questionnaire. Palo Alto, CA: Mind Garden.

* Bellamy, A. R., \& Bellamy, A. R. (2003). Emotional intelligence and transformational leadership: Recursive leadership processes within the context of employee work attitudes. Paper presented at the Midwest Academy of Management.

* BeShears, R. S. (2004). The ability of emotional intelligence to predict transformational leadership when personality, affect, and cognitive ability are controlled. Unpublished dissertation, Wayne State University, Detroit, MI.

Boehm, C. (1999). Hierarchy in the forest: The evolution of egalitarian behavior. Cambridge, MA: Harvard University Press.

Bono, J., \& Judge, T. (2004). Personality and transformational and transactional leadership: A meta-analysis. Journal of Applied Psychology, 89, 901-910.

Brackett, M., \& Mayer, J. (2003). Convergent, discriminant, and incremental validity of competing measures of emotional intelligence. Personality and Social Psychology Bulletin, 29, 1147-1158.

* Brown, F. W., Bryant, S. E., \& Reilly, M. D. (2006). Does emotional intelligence-as measured by the EQI-influ- ence transformational leadership and/or desirable outcomes? Leadership and Organization Development Journal, 27, 330-351.

Brown, F. W., \& Moshavi, D. (2005). Transformational leadership and emotional intelligence: A potential pathway for an increased understanding of interpersonal influence. Journal of Organizational Behavior, 26, 867-871.

* Buford, B. A. (2001). Management effectiveness, personality, leadership, and emotional intelligence: A study of the validity evidence of the emotional quotient inventory. Unpublished dissertation, University of Iowa, Iowa City.

* Burbach, M. E. (2004). Testing the relationship between emotional intelligence and full-range leadership as moderated by cognitive style and self-concept. Unpublished dissertation, University of Nebraska, Lincoln.

* Butler, C. J., \& Chinowsky, P. S. (2006). Emotional intelligence and leadership behavior in construction executives. Journal of Marketing in Engineering, 7, 119-125.

* Coetzee, C., \& Schaap, P. (2005). The relationship between leadership behavior, outcomes of leadership and emotional intelligence. South African Journal of Industrial Psychology, 31, 31-38.

* Condren, T., Martin, B., \& Huchinson, S. (2006). What does emotional intelligence and gender have to do with leadership effectiveness ... Or does it? Advancing Women in Leadership On-line Journal, 21.

* Cook, R. (2006). The effects of emotional intelligence on principals' leadership performance. Unpublished dissertation, Montana State University.

* Curry, S. M. (2004). Examining the relationship between selfperceived emotional intelligence and leadership in school principals. Unpublished dissertation, Regent University, Virginia Beach, VA.

* D'Alessio, F. (2006). The influence of personality, critical thinking, and emotional intelligence in Peruvian managers' leadership. Unpublished dissertation, University of Phoenix.

* Danehy, L. S. (2005). The relationship between emotional intelligence and leadership in NCAA division III college coaches. Unpublished dissertation, Wilmington College, Wilmington, $\mathrm{OH}$.

Daus, C., \& Ashkanasy, N. (2005). The case for the abilitybased model of emotional intelligence in organizational behavior. Journal of Organizational Behavior, 26, 453-466.

Day, A., \& Carroll, S. (2008). Faking emotional intelligence (EI): Comparing response distortion on ability and trait-based measures. Journal of Organizational Behavior, 29, 761-784. v* Donahue, R., \& Stevensen, L. (2006, July 1-4). The relationship between emotional intelligence and individual advancement and the mediating role of transformational leadership. Paper presented at the ACREW Conference, Tuscany, Italy.

* Downey, L. A., Papageorgiou, V., \& Stough, C. (2006). Examining the relationship between leadership, emotional intelligence, and intuition in senior female managers. Leadership and Organization Development Journal, 27, 250-264. 
* Elbers, N. (2007). Charismatic leadership, emotional intelligence and values in organizations. Unpublished dissertation, Erasmus University, Rotterdam.

* Ellis, M. (2007). The bilateral dimensions of transformational leadership in selected university constituents: An empirical study within the context of institutions of higher education. Unpublished dissertation, Capella University.

* Fox, K., Staebler Tardino, V., \& Maloney, P. (2008). The impact of ability and trait based emotional intelligence on transformational leadership behaviors. Paper presented at the meeting of the Society for Industrial and Organizational Psychology, San Francisco, CA.

Funder, D. (1995). On the accuracy of personality judgment: A realistic approach. Psychological Review, 102, 652-670.

* Gardner, L., \& Stough, C. (2002). Examining the relationship between leadership and emotional intelligence in senior level managers. Leadership and Organization Development Journal, 23, 68-78.

George, J. M. (2000, August). Emotions and leadership: The role of emotional intelligence. Human Relations, 53(8), 1027-1054.

Goleman, D. (1995). Emotional intelligence. New York: Bantam.

Goleman, D., Boyatzis, R., \& McKee, A. (2002). Primal leadership: Realizing the power of emotional intelligence. Boston: Harvard Business School Press.

* Groves, K. S. (2005a). Gender differences in social and emotional skills and charismatic leadership. Journal of Leadership and Organizational Studies, 11, 30-46.

* Groves, K. S. (2005b). Linking leader skills, follower attitudes, and contextual variables via an integrated model of charismatic leadership. Journal of Management, 31, 255-277.

* Groves, K. S. (2006). Leader emotional expressivity, visionary leadership, and organizational change. Leadership and Organization Development Journal, 27, 566-583.

* Hartsfield, M. (2003). The internal dynamics of transformational leadership: Effects of spirituality, emotional intelligence, and self-efficacy. Unpublished dissertation, Regent University, Virginia Beach, VA.

* Hayashi, A., \& Ewert, A. (2006). Outdoor leaders' emotional intelligence and transformational leadership. Journal of $E x-$ periential Education, 28, 222-242.

* Higgs, M., \& Aitken, P. (2003). An exploration of the relationship between emotional intelligence and leadership potential. Journal of Managerial Psychology, 18, 814-823.

Hoffman, B. J., \& Frost, B. C. (2006). Multiple intelligences of transformational leaders: An empirical investigation. International Journal of Manpower, 27, 37-51.

Hogan, R., Curphy, G., \& Hogan, J. (1994). What we know about leadership: Effectiveness and personality. American Psychologist, 49, 493-504.

Hunter, J., \& Schmidt, F. (1990). Methods of meta-analysis. Newbury Park, CA: Sage.
Hunter, J., \& Schmidt, F. (2004). Methods of meta-analysis: Correcting error and bias in research findings (2nd ed.). Thousand Oaks, CA: Sage.

* Hur, Y. H. (2009). Optimizing managerial effectiveness through emotional intelligence. Unpublished dissertation, University of Twente, The Netherlands.

* Jacques, F. (2002). An examination of the relationship between self-differentiation and transformational leadership, through the lens of emotional intelligence. Unpublished dissertation, University of Calgary, Alberta, Canada.

John, O., \& Robins, R. (1993). Determinants of interjudge agreement on personality traits: The Big Five domains, observability, evaluativeness, and the unique perspective of the self. Journal of Personality, 61, 521-551.

Jordan, P., Ashton-James, C., \& Ashkanasy, N. (2006). Evaluating the claims: Emotional intelligence in the workplace. In K. Murphy (Ed.), A critique of emotional intelligence: What are the problems and how can they be fixed? (pp. 189-210). Mahwah, NJ: Lawrence Erlbaum.

Judge, T., \& Piccolo, R. (2004). Transformational and transactional leadership: A meta-analytic test of their relative validity. Journal of Applied Psychology, 89, 755-768.

* Kanne, D. W. (2005). Emotional intelligence and the transformational learning journey of 30 senior pastors who participated in $L E A D$. Unpublished dissertation, Regent University, Virginia Beach, VA.

Kemper, C. L. (1999). EQ vs. IQ. Communication World, 16, 15- 22.

Kouzes, J., \& Posner, B. (2003). Leadership Practices Inventory (3rd ed.). San Francisco: Pfeiffer.

Landy, F. (2005). Some historical and scientific issues related to research on emotional intelligence. Journal of Organizational Behavior, 26, 411-424.

* Leban, W. V. (2003). The relationship between leader behavior and emotional intelligence of the project manager and the success of complex projects. Unpublished dissertation, Benedictine University, Lisle, IL.

* Legier, J. T. (2007). Assessing leadership effectiveness: The relationship between emotional intelligence and leadership behaviors on group and organizational performance. Unpublished dissertation, Southern Illinois University, Carbondale.

Lindebaum, D. (2009). Rhetoric or remedy? A critique on developing emotional intelligence. Academy of Management Learning \& Education, 8, 225-237.

Locke, E. (2005). Why emotional intelligence is an invalid concept. Journal of Organizational Behavior, 26, 425-431.

* Lugo, M. (2007). An examination of cultural and emotional intelligences in the development of global transformational leadership skills. Unpublished dissertation, Walden University.

* Macik-Frey, M. (2007). Communication centered approach to leadership, the relationship of interpersonal communication competence to transformational leadership and emotional intelligence. Unpublished dissertation, The University of Texas at Arlington. 
* Mandell, B., \& Pherwani, S. (2003). Relationship between emotional intelligence and transformational leadership style: A gender comparison. Journal of Business and Psychology, 17, 387-404.

Matthews, G., Zeidner, M., \& Roberts, R. (2002). Emotional intelligence: Science and myth. Cambridge, MA: MIT Press.

Mayer, J., Salovey, P., \& Caruso, D. (2002). Mayer-Salovey- Caruso Emotional Intelligence Test (MSCEIT) users manual. Toronto, Canada: Multi-Health Systems.

Mayer, J., Salovey, P., \& Caruso, D. (2004). Emotional intelligence: Theory, findings, and implications. Psychological Inquiry, 15, 197-215.

* Meredith, C. L. (2007). The relationship of emotional intelligence and transformational leadership behavior in non-profit executive leaders. Unpublished dissertation, Capella University.

* Middleton, K. (2005). The service-learning project as a supportive context for charismatic leadership emergence in nascent leaders. Academy of Management Learning and Education, 4, 295-308.

Mosier, C. (1943). On the reliability of a weighted composite. Psychometrika, 8, 161-168.

* Moss, S., Ritossa, D., \& Ngu, S. (2006). The effect of follower regulatory focus and extraversion on leadership behavior: The role of emotional intelligence. Journal of Individual Differences, 27, 93-107.

* Murensky, C. L. (2000). The relationships between emotional intelligence, personality, critical thinking ability, and organizational leadership performance at upper levels of management. Unpublished dissertation, George Mason University, Fairfax, VA.

* Nishiyama, Y. (2006). Gender, emotional intelligence and leadership styles of Japanese managers. Unpublished dissertation, University of Hawaii.

* Nowack, K. M. (2009). Unpublished raw data. (Available from Envisia Learning, Santa Monica, CA)

Nye, C. (2008). The powers to lead. New York: Oxford University Press.

Oswald, F. L., \& Johnson, J. W. (1998). On the robustness, bias, and stability of statistics from meta-analysis of correlation coefficients: Some initial Monte Carlo findings. Journal of Applied Psychology, 83, 164-178.

Palmer, B., \& Stough, C. (2001). Workplace SUEIT: Swinburne University Emotional Intelligence Test-Descriptive report. Melbourne: Swinburne University, Organisational Psychology Research Unit, Australia.

* Palmer, B., Walls, M., Burgess, Z., \& Stough, C. (2001). Emotional intelligence and effective leadership. Leadership and Organization Development Journal, 22, 5-10.

Petrides, K., \& Furnham, A. (2000). On the dimensional structure of emotional intelligence. Personality and Individual Differences, 29, 313-320.

Petrides, K., \& Furnham, A. (2001). Trait emotional intelligence: Psychometric investigation with reference to established trait taxonomies. European Journal of Personality, 15, 425-448.
Petrides, K., Pita, R., \& Kokkinaki, F. (2007). The location of trait emotional intelligence in personality factor space. British Journal of Psychology, 98, 273-289.

Popper, M., Mayseless, O., \& Castelnovo, O. (2000). Transformational leadership and attachment. The Leadership Quarterly, 11, 267-289.

* Purkable, T. L. (2003). Emotional intelligence, leadership style, and coping mechanisms of executives. Unpublished dissertation, The Catholic University of America, Washington, DC.

* Reed, T. G. (2005). Elementary principal emotional intelligence, leadership behavior, and openness: An exploratory study. Unpublished dissertation, The Ohio State University, Columbus.

Roberts, B. W., Harms, P. D., Smith, J., Wood, D., \& Webb, M. (2006). Methods in personality psychology. In M. Eid, \& E. Diener (Eds.), Handbook of psychological assessment: A multimethod perspective (pp. 321-335). Washington, DC: American Psychological Association.

* Rubin, R. S. (2003). Paddling upstream in leadership research: Exploring antecedents of transformational leadership behavior. Unpublished dissertation, Saint Louis University, St. Louis, MO.

Rubin, R. S., Munz, D. C., \& Bommer, W. H. (2005). Leading from within: The effects of emotion recognition and personality on transformational leadership. Academy of Management Journal, 48, 845-858.

Sadri, G., Weber, T., \& Gentry, W. (2008). Empathy as a crosscultural leadership behavior: An empirical analysis. Unpublished manuscript.

Salovey, P., \& Mayer, J. (1990). Emotional intelligence. Imagination, Cognition, and Personality, 9, 185-211.

Sashkin, M. (2004). Transformational leadership approaches. In J. Antonakis, A. Ciancolo, \& R. Sternberg (Eds.), The nature of leadership (pp. 171-196). Thousand Oaks, CA: Sage.

* Schechter, A. F. (2005). The influence of transformational leadership, emotional intelligence, trust, meaning and intention to quit on organizational citizenship behavior. Unpublished dissertation, University of Stellenbosch, South Africa.

* Schmitz, S. A. (2004). The relationship between emotional intelligence and leadership practices in non-profit human service organizations. Unpublished dissertation, Northcentral University, Prescott Valley, AZ.

* Schulte, M. J. (2002). Emotional intelligence: A predictive or descriptive construct in ascertaining leadership style or a new name for old knowledge. Unpublished dissertation, Our Lady of the Lake University, San Antonio, TX.

Schutte, N., Malouff, J., Thorsteinsson, E., Bhullar, N., \& Rooke, S. (2007). Meta-analytic investigation of the relationship between emotional intelligence and health. Cognition and Emotion, 16, 769-785.

* Sivanathan, N., \& Fekken, G. C. (2002). Emotional intelligence, moral reasoning, and transformational leadership. Leadership and Organization Development Journal, 23, 198-204. 
Sosik, J. J., \& Megarian, L. E. (1999). Understanding leader emotional intelligence and performance: The role of selfother agreement on transformational leadership perceptions. Group Organization Management, 24, 367-390.

Spector, P. (2005). Introduction: Emotional intelligence. Journal of Organizational Behavior, 26, 409-410.

* Srivsastatava, K. B. L., \& Bharamanaikar, S. R. (2004). Emotional intelligence and effective leadership behavior. $\mathrm{Na}$ tional Academy of Psychology, India, 49, 107-113.

* Tang, H. V. (2007). A cross-cultural investigation of academic leaders' emotional intelligence and leadership effectiveness in Taiwan and the United States. Unpublished dissertation, Texas A\&M University-Kingsville and Texas A\&M University-Corpus Christi.

Turner, N., Barling, J., Epitropaki, O., Butcher, V., \& Milner, C. (2002). Transformational leadership and moral reasoning. Journal of Applied Psychology, 87, 304-311.

Van Rooy, D., \& Viswesvaran, C. (2004). Emotional intelligence: A meta-analytic investigation of predictive validity and nomological net. Journal of Vocational Behavior, 65, 71-95.

* Vrba, M. (2007). Emotional intelligence skills and leadership behavior in a sample of South African first-line managers. Management Dynamics, 16, 25-35.

Watson, D., Hubbard, B., \& Wiese, D. (2000). Self-other agreement in personality and affectivity: The role of acquaintanceship, trait visibility, and assumed similarity. Journal of Personality and Social Psychology, 78, 546-558.

* Webb, S. (2005). Examining emotional intelligence and leadership. Unpublished dissertation, University of South Florida, Tampa.

Weinberger, L. A. (2004, March 3-7). An examination of the relationship between emotional intelligence and leadership style. Paper presented at the Academy of Human Resource Development International Conference, Austin, TX.

Wong, C., \& Law, K. S. (2002). The effects of leader and follower emotional intelligence on performance and attitude: An exploratory study. The Leadership Quarterly, 13, 243-274.

* Wu, W., Liu, Y., Song, L. J., \& Liu, J. (2006). Effects of organizational leadership on employee commitment: The moderating role of emotional intelligence. Journal of Psychology in Chinese Societies, 7, 283-306.

\section{$\langle\langle\langle\langle\langle\langle\rangle\rangle\rangle\rangle\rangle\rangle$}

P. D. Harms is an Assistant Professor of Management at the University of Nebraska-Lincoln. His primary research interests include personality and leadership development, status attainment, power motivation, and the psychological experience of leadership.

Marcus Credé is an Assistant Professor of Psychology at the State University of New York at Albany. His primary research interests include non-cognitive predictor of performance in academic and work settings, the structure of such non-cognitive predictors and the nature of performance, as well as issues relating to the measurement of non-cognitive attributes and performance. 